\title{
Caracterização da comunidade bacteriana endofítica de citros por isolamento, PCR específico e DGGE
}

\author{
Paulo Teixeira Lacava(1), Fernando Dini Andreote(1), Welington Luiz Araújo(1) e João Lúcio Azevedo(1)
}

(1)Escola Superior de Agricultura Luiz de Queiroz, Dep. de Genética, Av. Pádua Dias, o 11, Caixa Postal 83, CEP $13400-970$ Piracicaba, SP.
E-mail: ptlacava@esalq.usp.br, fdandreo@esalq.usp.br, wlaraujo@esalq.usp.br, jazevedo@esalq.usp.br

\begin{abstract}
Resumo - O objetivo deste trabalho foi caracterizar a comunidade bacteriana endofítica de plantas assintomáticas (escapes) e afetadas pela clorose variegada dos citros (CVC) por meio de isolamento em meio de cultura, técnica de gradiente desnaturante em gel de eletroforese (DGGE) e detecção de Methylobacterium mesophilicum e Xyllela fastidiosa por meio de PCR específico, para estudar esta comunidade e sua relação com a ocorrência da CVC. A análise da comunidade bacteriana via DGGE permitiu a detecção de $X$. fastidiosa, bem como Klebsiella sp. e Acinetobacter sp. como endófitos de citros. Foram observados também Curtobacterium sp., Pseudomonas sp., Enterobacter sp. e Bacillus spp. Utilizando primers específicos, Methylobacterium mesophilicum e X. fastidiosa também foram observadas, reforçando hipóteses de que estas bactérias podem estar interagindo no interior da planta hospedeira.
\end{abstract}

Termos para indexação: Citrus sinensis, Xylella fastidiosa, Methylobacterium, bactérias endofíticas.

\section{Characterization of the endophytic bacterial community from citrus by isolation, specific PCR and DGGE}

\begin{abstract}
The aim of this work was to characterize endophytic bacterial community of assintomatic (escape) and Citrus Variegated Chlorosis (CVC)-affected citrus plants using isolation in culture medium, denaturing gradient gel electrophoresis (DGGE) technique and Methylobacterium mesophilicum as well as Xylella fastidiosa specific PCR, allowing to assess this community and its interactions with CVC. The study of bacterial community by DGGE analysis allowed the detection of $X$. fastidiosa, as well as Klebsiella sp. e Acinetobacter sp., which were not detected previously. Curtobacterium sp., Pseudomonas sp., Enterobacter sp. and Bacillus spp. were also observed as endophyte in citrus plants. Using specific primers Methylobacterium mesophilicum and $X$. fastidiosa were observed, reinforcing that these bacteria could interact inside the host plant.
\end{abstract}

Index terms: Citrus sinensis, Xylella fastidiosa, Methylobacterium, endophytic bacteria.

\section{Introdução}

Endófitos são microrganismos que habitam o interior das plantas, sendo encontrados em órgãos e tecidos vegetais como folhas, ramos e raízes sem causar doenças e sem produzir estruturas externas visíveis (Azevedo et al., 2000). A comunidade endofítica é constituída principalmente por fungos e bactérias que, ao contrário dos microrganismos patogênicos, não causam prejuízo à planta hospedeira (Peixoto Neto et al., 2002).

Com o acúmulo de informações sobre a interação planta-endófitos (Azevedo et al., 2000; Araújo et al., 2001), e com a determinação das diferentes funções desses microrganismos no interior da planta, tem sido dada atenção ao estudo de bactérias endofíticas, que podem atuar no controle biológico de inúmeras doenças
(Hallmann et al., 1997; M’Piga et al., 1997), na promoção de crescimento vegetal (Hallmann et al., 1997; Bent \& Chanway, 1998), e na biorremediação de áreas poluídas (Newman \& Reynolds, 2005).

As técnicas utilizadas para avaliar a comunidade endofítica de plantas não permitem o estudo de microrganismos não cultiváveis, restringindo os estudos a espécies cultivadas, que na maioria são conhecidas. A fim de melhorar a caracterização e a análise destas comunidades, independentemente do cultivo das espécies que as compõem, o interesse tem sido focado no desenvolvimento de técnicas de biologia molecular capazes de permitir o estudo da comunidade endofítica em seu habitat. A análise do gene de 16S rRNA tem sido utilizada no estudo de microrganismos do ambiente (Amann et al., 1995), e, entre as metodologias baseadas no 
16S rDNA, destaca-se o gradiente desnaturante em gel de eletroforese (DGGE). Esta técnica identifica diferenças estabelecidas no comportamento desnaturante da dupla fita de DNA que, submetida a um gradiente crescente de concentração de agentes desnaturantes (uréia e formamida), se separam em fragmentos discretos, chamados de domínios de desnaturação.

A técnica de DGGE tem se destacado e é utilizada em diferentes habitats com sucesso (Muyzer et al., 1993; El Fantroussi et al., 1999; Yang \& Crowley, 2000), detectando alterações na comunidade microbiana decorrente da presença de agroquímicos (El Fantroussi et al., 1999), estado nutricional e fisiológico da planta hospedeira (Henckel et al., 1999; Yang \& Crowley, 2000) e transgenia do hospedeiro (Heuer \& Smalla, 1997). Sua aplicabilidade se relaciona ao estudo de comunidades endofíticas, como demonstrou Garbeva et al. (2001), ao determinar tanto a população cultivável como as espécies não cultiváveis que colonizam o Solanum tuberosum.

Araújo et al. (2002) demonstraram que o DGGE pode auxiliar no estudo da comunidade endofítica de citros, permitindo avaliar o efeito de bactérias endofíticas sobre os endófitos naturais de citros, independentemente da capacidade desses microrganismos crescerem ou não em meio de cultura. Araújo et al. (2002) avaliaram também, por DGGE, a comunidade bacteriana endofítica de plantas afetadas pela clorose variegada dos citros (CVC) - doença cujo agente causal é a bactéria Xylella fastidiosa -, plantas sadias, plantas assintomáticas para a CVC em pomares afetados (escapes) e tangerina Ponkan (naturalmente resistente à CVC), verificando maior diversidade na população de bactérias da classe das $\beta$-proteobactéria endofíticas de plantas afetadas em relação às demais.

Os objetivos deste trabalho foram o isolamento da comunidade bacteriana endofítica, utilizando meios de cultura gerais e específicos, a caracterização da comunidade endofítica de plantas assintomáticas (escapes) e afetadas pela CVC, por meio da técnica de DGGE, e a detecção de Methylobacterium mesophilicum (endófito) e $X$. fastidiosa, por meio de PCR específico.

\section{Material e Métodos}

O material vegetal utilizado foi proveniente da cidade de Bebedouro, SP, e fornecido pelo Fundo de Defesa da Citricultura (Fundecitrus). Foram utilizados ramos de Citrus sinensis (variedade Natal), de aproximadamen- te $0,5 \mathrm{~cm}$ de diâmetro, coletados em plantas com sintomas da CVC, escapes e sadias.

No isolamento de microrganismos, foi realizada primeiramente desinfecção superficial dos tecidos vegetais. Os ramos foram lavados em água corrente e desinfectados por meio de imersões sucessivas em etanol $70 \%$ por um minuto, solução de hipoclorito de sódio $2 \%$ por cinco minutos, etanol $70 \%$ por 30 segundos e dois enxágües em água destilada (Araújo et al., 2001). Alíquotas da água utilizada no enxágüe foram semeadas sobre meio TSA (Trypic Soy Agar) 5\% para avaliar a eficiência da desinfecção superficial.

O isolamento foi realizado por meio do pressionamento de fragmentos das plantas sobre o meio não seletivo TSA 5\% (Araújo et al., 2001) e sobre o meio específico para bactérias metilotróficas Choi (Toyama et al., 1998), suplementados com benomil (50 $\mu \mathrm{g} \mathrm{mL}^{-1}$ ) para inibição do crescimento fúngico. Em seguida, as placas foram incubadas a $28^{\circ} \mathrm{C}$ por até 30 dias, quando foi observado o crescimento das colônias. A incidência de endofíticos foi calculada de acordo com o número de fragmentos que apresentaram crescimento microbiano em relação ao número total de fragmentos vegetais avaliados.

A análise de DGGE constou da comparação das comunidades endofíticas em ramos de plantas de citros utilizadas no isolamento. Para isto, realizou-se extração de DNA total dos ramos de citros, assim como de culturas puras, utilizadas como marcadores na eletroforese. Como marcadores foram empregados isolados das bactérias endofíticas de citros Methylobacterium extorquens (isolado AR1.6/2), M. mesophilicum (isolado SR1.6/6), Curtobacterium flaccumfaciens (isolado ER1/6) e $X$. fastidiosa (linhagem 9a5c), da coleção do Laboratório de Genética de Microrganismos da Esalq.

As extrações de DNA de culturas bacterianas e de tecidos vegetais foram realizadas segundo Araújo et al. (2002). O DNA obtido foi submetido à amplificação em PCR com volume de $50 \mu \mathrm{L}$, contendo $2 \mu \mathrm{L}$ ( 0,5 a $10 \mathrm{ng}$ ) de DNA molde, 0,2 $\mu \mathrm{M}$ dos primers R1378 e F968 $\perp$ GC (Tabela 1); $200 \mu \mathrm{M}$ de cada dCTP, dGTP, dATP e dTTP (Pharmacia); 3,75 mM de $\mathrm{MgCl}_{2}$; 5,0 U de Taq DNA polimerase (Life Technologies) em $50 \mathrm{mM} \mathrm{KCl}$ e $20 \mathrm{mM}$ Tris-HCl, pH 8,4. A mistura foi colocada em termociclador PTC-100 (MJ Reserch, Inc. USA), programado para gerar uma desnaturação inicial de quatro minutos a $94^{\circ} \mathrm{C}$, e 30 ciclos de $94^{\circ} \mathrm{C}$, um minuto; $56^{\circ} \mathrm{C}$, um minuto; $72^{\circ} \mathrm{C}$, dois minutos; seguidos de uma extensão final de dez minutos a $72^{\circ} \mathrm{C}$. Depois do término, $5 \mu \mathrm{L}$ 
da reação foram utilizados para observação em gel de agarose $(1,2 \%)$ de um fragmento de aproximadamente $450 \mathrm{pb}$.

A análise por DGGE foi realizada conforme Muyzer et al. (1993) e adaptada por Araújo et al. (2002) no sistema DGGE-1001 (C.B.S., Scientific Company, INC., USA). Os produtos de PCR foram colocados em gel vertical de poliacrilamida a $6 \%$ com gradiente desnaturante de uréia/formamida de $45-80 \%$, a $60^{\circ} \mathrm{C}$, numa eletroforese de 15 horas a $100 \mathrm{~V}$. Em seguida, o gel foi corado com SYBR Gold (diluído 1:10.000; Gold Nucleic Acid Gel Stain; Molecular Probes, Eugene, Oregon, USA) e observado em luz ultravioleta.

As bandas obtidas nas diferentes amostras foram selecionadas e cortadas do gel com auxílio de bisturi e colocadas em microtubos de 1,5 mL. O fragmento de gel contendo a banda foi macerado em $10 \mu \mathrm{L}$ de água deionizada esterilizada, e $1 \mu \mathrm{L}$ utilizado na PCR para reamplificação da banda. Essas reações foram realizadas com os mesmos padrões da anterior, porém com os primers F968」GC e R1378 (Tabela 1). Depois da amplificação, os produtos de PCR foram purificados com o kit GFX PCR (Amersham Pharmacia Biotech), clonados no plasmídio pGEM-T (pGEM-T Easy Vector, System I, Promega) e inseridos em Escherichia coli DH5 $\alpha$. O plasmídio contendo o inserto de interesse foi extraído por lise alcalina (Sambrook et al., 1989) e analisado em gel de agarose (1\%). As amostras contendo o inserto de tamanho esperado foram então seqüenciadas. A seqüência foi analisada por similaridade com as depositadas no GenBank (NCBI, 2001), verificando as que revelavam maiores similaridades com as obtidas.

A detecção do endófito $M$. mesophilicum em tecidos vegetais foi feita por PCR, utilizando os primers R1378 e MMV6 (Tabela 1), enquanto a detecção de $X$. fastidiosa foi realizada com os primers descritos por Pooler \& Hartung (1995).

\section{Resultados e Discussão}

No isolamento de bactérias cultiváveis endofíticas de ramos de citros, em meio não seletivo (TSA 5\%), foi observada uma comunidade bacteriana constituída basicamente de três grupos morfológicos: amarelas, brancas e Bacillus spp. (Figura 1). O grupo morfológico das bactérias amarelas apresentou maior freqüência de isolamento em plantas afetadas em relação às demais, enquanto o grupo morfológico das brancas e Bacillus spp. mostraram populações semelhantes em todas as plantas. A bactéria Methylobacterium spp. foi isolada apenas utilizando o meio CHOI3. Esta bactéria endofítica apresentou incidência que diminuiu na seguinte ordem: plantas com sintomas da CVC > assintomáticas > sadias, sugerindo a interação deste endófito com $X$. fastidiosa, no interior da planta hospedeira. Resultado semelhante foi observado por Araújo et al. (2002), enquanto Lacava et al. (2004) descreveram o efeito positivo de metabólitos produzidos por Methylobacterium sp. no desenvolvimento de $X$. fastidiosa, revelando uma simbiose entre estas espécies, que poderia resultar no desenvolvimento dos sintomas da CVC.

A análise de DGGE revelou presença de endófitos em todas as plantas amostradas (Figura 2), sendo observadas pequenas alterações de acordo com a condição fitossanitária em relação à CVC de cada material vegetal. As bandas selecionadas para análise e identificação por seqüenciamento podem ser observadas na Figura 2. Os resultados revelaram presença de espécies descritas e cultivadas de endófitos de citros e também espécies ainda não descritas como colonizadoras deste hospedeiro.

Entre os gêneros anteriormente descritos como endófitos de citros, na análise de DGGE, foi possível detectar a presença de Curtobacterium (banda b), Pseudomonas (banda d), Enterobacter (banda e) e Enterobacteriacea (bandas g), além do patógeno $X$. fastidiosa (banda a), detectado em uma das plantas afetadas. Por esta análise via DGGE, foram observadas Klebsiella (banda h) e Acinetobacter (banda f), em plantas afetadas e sadias, respectivamente. A banda c foi identificada como cloroplasto (Figura 2). Este resultado mostra a importância da utilização de diferentes

Tabela 1. Seqüências dos primers utilizados para a detecção de Methylobacterium mesophilicum e Xylella fastidiosa e em análises de DGGE.

\begin{tabular}{lcc}
\hline Primer $^{(1)}$ & DNA alvo (posição) & Seqüência $^{(2)}{ }^{\prime} \rightarrow 3^{\prime}$ \\
\hline F968 $\perp$ GC & Bactéria; 16S rDNA (968) & CGCCCGGGGCGCGCCCCGGGCGGGGCGGGGGCACGGGGGG-AACGCGAAGAACCTTAC $^{(3)}$ \\
R1378 & Bactéria; 16S rDNA (1401) & CGGTGTGTACAAGGCCCGGGAACG \\
CVC-1 & X. fastidiosa & AGATGAAAACAATCATGCAAA \\
272-2 in & X. fastidiosa & GCCGCTTCGGAGAGCATTCCT \\
MMV6 & M. mesophilicum; 16 S rDNA & ACGTGGAGAGATTCACGG \\
\hline
\end{tabular}

${ }^{(1)}$ F, primer 5’; R, primer 3'. (2)Posições de acordo com o anelamento no gene 16S rRNA de E. coli. (3)5’ grampo de GC (seqüência anterior ao hífen). 
métodos para a análise de comunidades microbianas, visto que a utilização de apenas um meio de cultura pode

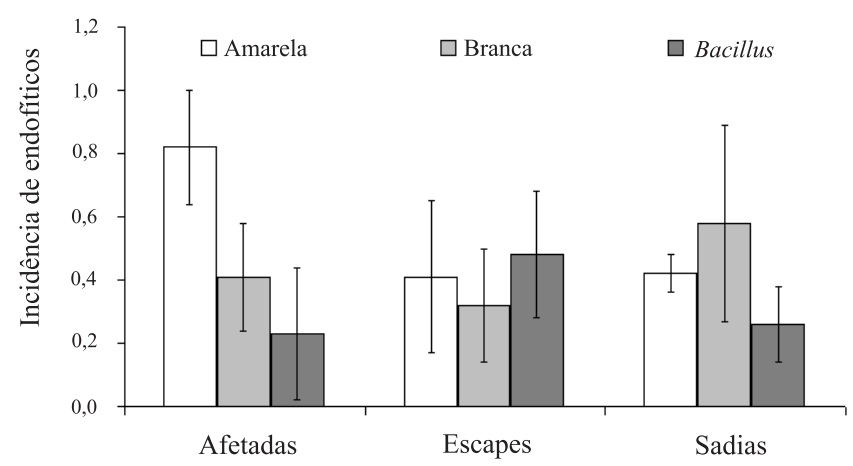

Figura 1. Incidência de endofíticos em ramos de Citrus sinensis no isolamento em meio TSA 5\%. Os resultados são médias de três repetições e as barras indicam o desvio-padrão. inviabilizar a observação de inúmeras espécies incapazes de crescer nessas condições, subestimando, dessa forma, a diversidade presente.

O DNA da análise de DGGE foi também utilizado na detecção de $M$. mesophilicum e $X$. fastidiosa por PCR, utilizando iniciadores específicos. Esta análise foi capaz de detectar a presença de $X$. fastidiosa em metade das plantas afetadas (4/8), além da presença de uma banda de intensidade baixa em uma das plantas escapes (Tabela 2). Já a espécie $M$. mesophilicum foi detectada em aproximadamente 70\% das amostras (10/14). A baixa freqüência de detecção de $M$. mesophilicum em plantas afetadas pela CVC (3/6) pode sugerir que, embora pertença ao gênero Methylobacterium, essa espécie pode interagir de forma diferente com $X$. fastidiosa. Estes resultados reforçam a noção de que os sintomas da CVC poderiam ser resultado do balanço populacional entre endófitos, como Methylobacterium

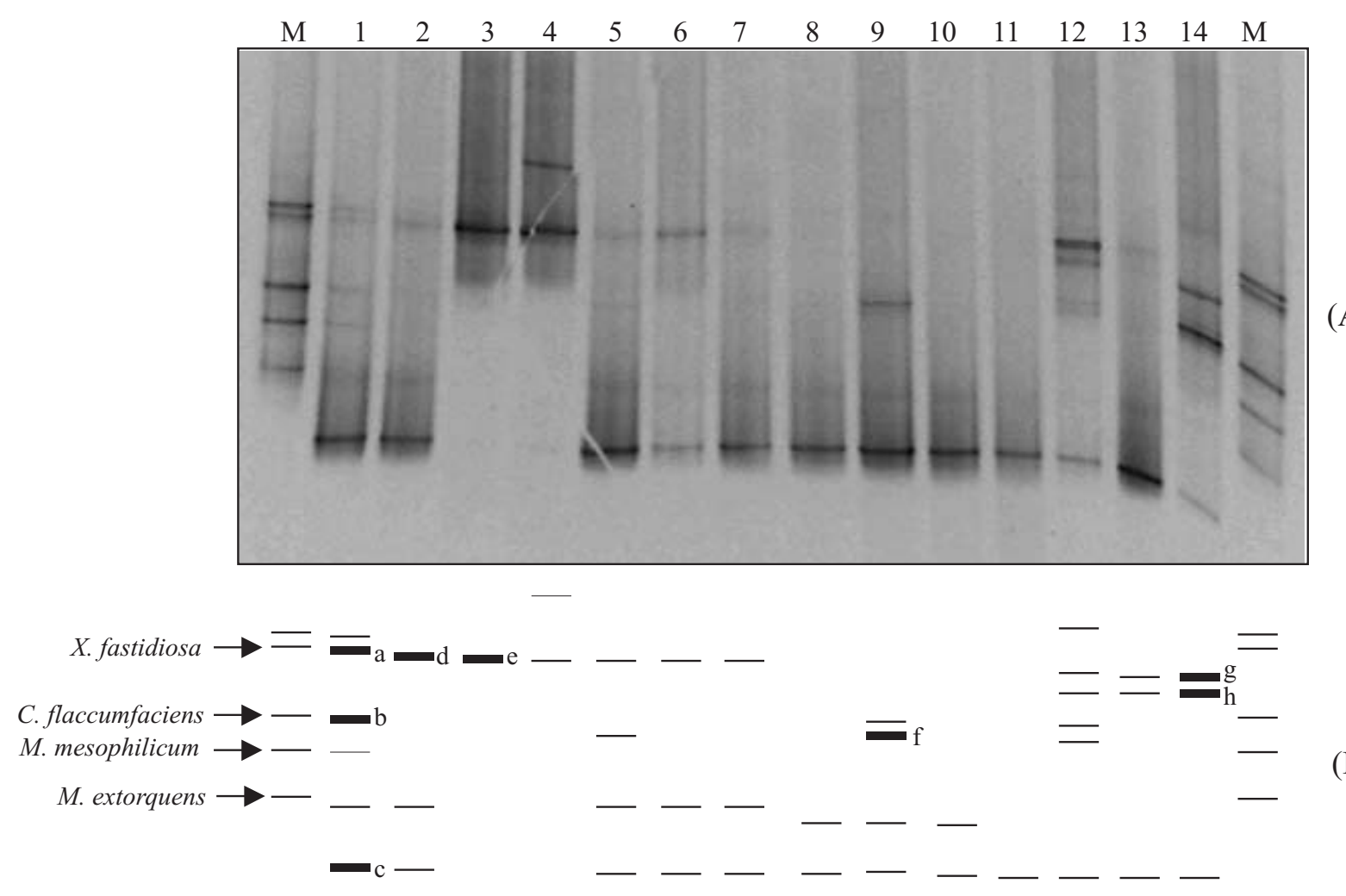

(A)

Figura 2. A) Perfil eletroforético de DGGE da comunidade endofítica de Citrus sinensis: M é marcador composto da mistura de endófitos e Xylella fastidiosa; 1 a 6 e 14 são plantas afetadas pela CVC; 7 a 9 são plantas sadias e 10 a 13 são plantas escapes; B) em negrito estão representadas as bandas selecionadas para seqüenciamento de cada tratamento. 
Tabela 2. Resultados de PCR com primers específicos para detecção de Methylobacterium mesophilicum e Xylella fastidiosa a partir de DNA extraído de ramos de citros.

\begin{tabular}{lcccc}
\hline Espécie detectada & \multicolumn{4}{c}{ Plantas } \\
\cline { 2 - 5 } & Afetadas & Escapes & Sadias & Total \\
\hline$X$. fastidiosa & $4 / 8$ & $1 / 3$ & $0 / 3$ & $5 / 14$ \\
M. mesophilicum & $3 / 6$ & $3 / 4$ & $4 / 4$ & $10 / 14$ \\
\hline
\end{tabular}

spp. e $X$. fastidiosa (Araújo et al., 2002; Lacava et al., 2004).

A comunidade endofítica de citros foi caracterizada com base em diferentes técnicas. A técnica de isolamento revelou os principais endófitos culturáveis de citros, como anteriormente realizado por Araújo et al. (2001) e Andreote et al. (2004), que observaram alterações na comunidade natural de plântulas de citros depois da inoculação de endófitos geneticamente modificados. Conforme descrito para batata (Garbeva et al., 2001) e citros (Araújo et al., 2002), a técnica de DGGE permite a caracterização da comunidade bacteriana endofítica cultivável e não cultivável, mostrando espécies bacterianas não observadas pela técnica de isolamento. Em citros, Araújo et al. (2002) detectaram os gêneros Curtobacterium, Methylobacterium e Nocardia por isolamento e DGGE. Entretanto, estes autores encontraram a espécie Corynebacterium accolerans apenas por DGGE. Foi verificada a presença de Methylobacterium sp. colonizando tecidos internos do hospedeiro por meio de isolamento específico (CHOI3) e o uso de primers específicos, porém não foram encontradas bandas referentes a tal gênero na análise de DGGE, o que mostra a importância da utilização de técnicas diferentes no estudo de uma mesma comunidade bacteriana, a fim de se compreender melhor a ecologia desses microrganismos e suas interações com o hospedeiro.

\section{Conclusões}

1. A utilização de técnicas microbiológicas e moleculares permite melhor caracterização da comunidade bacteriana endofítica de citros.

2. A comunidade bacteriana endofítica de plantas de citros assintomáticas com sintomas da CVC é composta por Klebsiella sp., Acinetobacter sp., Curtobacterium sp., Pseudomonas sp., Enterobacter sp., Bacillus spp. e Methylobacterium mesophilicum.

3. Plantas de citros com sintomas da CVC são hospedeiros preferenciais de Methylobacterium spp.
4. O desenvolvimento da CVC é resultado da alteração na comunidade bacteriana endofítica, a qual interage de forma ativa com $X$. fastidiosa, sendo que Methylobacterium sp. parece interagir de forma sinergística para o desenvolvimento da CVC.

\section{Agradecimentos}

À Fapesp, pelo suporte financeiro e pelas bolsas concedidas para Paulo Teixeira Lacava e Welington Luiz de Araújo; ao Fundecitrus, pelo apoio financeiro.

\section{Referências}

AMANN, R.I.; LUDWIG, W.; SCHLEIFER, K.H. Phylogenetic identification and in situ detection of individual microbial cells without cultivation. Microbiological Reviews, v.59, p.143-169, 1995.

ANDREOTE, F.D.; GULLO, M.J.M.; LIMA, A.O. de S.; MACCHERONI JUNIOR, W.; AZEVEDO, J.L.; ARAÚJO, W.L. Impact of genetically modified Enterobacter cloacae on indigenous endophytic community of Citrus sinensis seedlings. Journal of Microbiology, v.42, p.169-173, 2004.

ARAÚJO, W.L.; MACCHERONI JUNIOR, W.; AGUILARVILDOSO, C.I.; BARROSO, P.A.V.; SARIDAKIS, H.O.; AZEVEDO, J.L. Variability and interactions between endophytic bacteria and fungi isolated from leaf tissues of citrus rootstocks. Canadian Journal of Microbiology, v.47, p.229-236, 2001.

ARAÚJO, W.L.; MARCON, J.; MACCHERONI JUNIOR, W.; ELSAS, J.D. van; VUURDE, J.W.L. van; AZEVEDO, J.L. Diversity of endophytic bacterial populations and their interaction with Xylella fastidiosa in citrus plants. Applied and Environmental Microbiology, v.68, p.4906-4914, 2002.

AZEVEDO, J.L.; MACCHERONI JUNIOR, W.; PEREIRA, J.O.; ARAÚJO, W.L. Endophytic microorganisms: a review on insect control and recent advances on tropical plants. Electronic Journal of Biotechnology, v.3, 2000. Disponível em: <http:// ejbiotechnology.info/content/vol3/issue1/index.html $>$. Acesso em: set. 2005.

BENT, E.; CHANWAY, C.P. The growth-promoting effects of a bacterial endophyte on lodgepole pine are partially inhibited by the presence of other rhizobacteria. Canadian Journal of Microbiology, v.44, p.980-988, 1998.

EL FANTROUSSI, S.; VERSCHUERE, L.; VERSTRAETE, W.; TOP, E.M. Effect of phenylurea herbicides on soil microbial communities estimated by analysis of 16S rRNA gene fingerprints and community-level physiological profiles. Applied and Environmental Microbiology, v.65, p.982-988, 1999.

GARBEVA, P.; OVERBEEK, L.S. van; VUURDE, J.W.L. van; ELSAS, J.D. van. Analysis of endophytic bacterial communities of potato by plating and denaturing gradient gel electrophoresis (DGGE) of 16S rDNA based PCR fragments. Microbial Ecology, v.41, p.369383, 2001. 
HALLMANN, J.; QUADT-HALLMANN, A.; MAHAFFEE, W.F.; KLOEPPER, J.W. Bacterial endophytes in agricultural crops. Canadian Journal of Microbiology, v.43, p.895-914, 1997.

HENCKEL, T.; FRIEDRICH, M.; CONRAD, R. Molecular analyses of the methane-oxidizing microbial community in rice field soil by targeting the genes of the 16S rRNA, particulate methane monooxygenase, and methanol dehydrogenase. Applied and Environmental Microbiology, v.65, p.1980-1990, 1999.

HEUER, H.; SMALLA, K. Application of denaturing gradient gel electrophoresis (DGGE) and temperature gradient gel electrophoresis (TGGE) for studying soil microbial communities. In: ELSAS, J.D. van; TREVORS, J.T.; WELLINGTON, E.M.H. (Ed.). Modern soil microbiology. New York: Marcel Dekker, 1997. p.353-373.

LACAVA, P.T.; ARAÚJO, W.L.; MARCON, J.; MACCHERONI JUNIOR, W.; AZEVEDO, J.L. Interaction between endophytic bacteria from citrus plants and the phytopathogenic bacteria Xylella fastidiosa, causal agent of citrus-variegated chlorosis. Letters in Applied Microbiology, v.39, p.55-59, 2004.

M’PIGA, P.; BÉLANGER, R.R.; PAULITZ, T.C.; BENHAMOU, N. Increased resistance to Fusarium oxysporum f. sp. radicislycopersici in tomato plants treated with the endophytic bacterium Pseudomonas fluorescens strain 63-28. Physiological and Molecular Plant Pathology, v.50, p.301-320, 1997.

MUYZER, G.; DE WAAL, E.C.; UITTERLINDEN, A.G. Profiling of complex microbial populations by denaturing gradient gel electrophoresis analysis of polymerase chain reaction-amplified genes coding for 16S rRNA. Applied and Environmental Microbiology, v.59, p.695-700, 1993.

NCBI. Blast database. 2001. Disponível em: <http://www.ncbi.nlm.nih.gov/BLAST/>. Acesso em: 20 ago. 2005.

NEWMAN, L.A.; REYNOLDS, C.M. Bacteria and phytoremediation: new uses for endophytic bacteria in plants. Trends in Biotechnology, v.23, p.6-8, 2005.

PEIXOTO NETO, P.A. de S.; AZEVEDO, J.L.; ARAÚJO, W.L. de. Microrganismos endofíticos. Biotecnologia Ciência \& Desenvolvimento, v.29, p.62-77, 2002.

POOLER, M.R.; HARTUNG, J.S. Specific PCR detection and identification of Xylella fastidiosa strains causing citrus variegated chlorosis. Current Microbiology, v.31, p.377-381, 1995.

SAMBROOK, J.; FRITSCH, E.F.; MANIATIS, T. Molecular cloning: a laboratory manual. $2^{\text {nd }}$ ed. Cold Spring Harbor, NY: Cold Spring Harbor Laboratory Press, 1989. 3v.

TOYAMA, H.; ANTHONY, C.; LIDSTROM, M.E. Construction of insertion and deletion mxa mutants of Methylobacterium extorquens AM1 by electroporation. FEMS Microbiology Letters, v.166, p.1-7, 1998.

YANG, C.H.; CROWLEY, D.E. Rhizosphere microbial community structure in relation to root location and plant iron nutritional status. Applied and Environmental Microbiology, v.66, p.345-351, 2000. 